\title{
A CLINICAL STUDY OF THE DRAUGHT REFLEX IN HUMAN LACTATION
}

\author{
BY \\ CLAIR ISBISTER* \\ From the Unit of Clinical Investigation and the Department of Obstetrics, the Royal North Shore Hospital of Sydney, \\ Australia
}

(RECEIVED FOR PUBLICATION AUGUST 5, 1953)

The problems of human lactation have lost their urgency and unfortunately even their interest for the majority of the medical profession since the introduction of safe and satisfactory artificial foods. But for thousands of lactating women the problems are no less acute now than they were for their ancestors. The joy and sense of achievement given by satisfactory lactation is no less real nor is the sense of dissatisfaction and personal inefficiency less acute because of the existence of satisfactory substitutes.

\section{History of the Draught Reflex}

The idea that milk flowed and was not merely sucked out was quite familiar in ancient and medieval times. Some of the best clinical observations on human lactation are to be found in the works of Avicenna (see Duncum, 1947), the 'prince of physicians', in Baghdad in the eleventh century. No modern textbook has anything to add to his care of the lactating woman, and there is no better description of the woman who lactates well than in his writings on 'the selection of a wet nurse'. Avicenna, writing on the flow of milk, says:

'If there is anything to prevent the mother from giving milk to her babe, such as because it runs too quickly . . . a wet nurse should be selected', and again 'A little milk may be drawn from the breast before each feed to encourage and facilitate its flow.'

Another reference to the flow of milk may be found in the records of the Hospital of the Holy Ghost in Rome, where there is a sixteenth century fresco illustrating a group of wet nurses feeding foundling children to the soothing accompaniment of a musician playing the renaissance equivalent of the oboe, the purpose of this music being 'the beneficial influence of soft and melodious music on the flow of mothers' milk!' Rubens' famous 'War and Peace' and Tintoretto's 'Milky Way' in the

\footnotetext{
* Working with a grant from the King George V and Queen Mary
} Maternal and Infant Welfare Foundation.
National Gallery, London, also incidently illustrate milk ejection.

Much of this knowledge has been lost or forgotten. In 1947 I made some detailed observations on the occurrence of the draught, or 'let-down' reflex, in my own third lactation and found that there was very little reference to it in the current literature, except in the writings of Waller $(1938,1943,1947 a$, 1947b). I discussed my findings with colleagues well versed in infant feeding and found that many had never heard of it. Those who had heard of it regarded it of little importance in the management of lactation and thought it occurred in only a few patients. My efforts to point out that it occurred very commonly resulted in the criticism that the highly suggestible, nervous puerperal woman will feel anything she is asked to, and I decided not to publish my observations without further confirmation. A year later a visit to the National Institute for Research in Dairying at Reading, England, made me familiar with the work of Folley (1947), Ely and Petersen, (1941) and Richardson (1947). Soon after this the first article of Newton and Newton (1948) confirmed my observations, and I decided to collect a series of patients in an effort to determine the normal pattern of the draught reflex, and, if possible, to observe its disturbances and whether they produced symptoms in the baby.

It is easy for most lactating women to observe that while the baby sucks at one breast, milk often flows from the other and a sensation of 'pins and needles' or 'drawing' occurs in the breasts. Ely and Petersen (1941) beautifully demonstrated the let-down reflex in dairy cattle as a reflex mechanism in which afferent nervous impulses from the teat are carried to the posterior pituitary gland. The oxytocic principle released probably causes contraction of myoepithelial cells surrounding the alveoli. Richardson (1947) stained these contractile cells in the goat. Since then the let-down reflex has been demostrated in many species (Whittlestone, Bassett and 
Turner, 1952; Whittlestone and Turner, 1952; Cross, 1952; Cross and Harris, 1952; Braude and Mitchell, 1952; Petersen and Ludwick, 1942). Other physiologists have more clearly demonstrated the path of the nervous impulses (Andersson, 1951) and the hormonal factors (Selye, Collip and Thomson, 1934; Selye and McKeown, 1934a and b). In the human subject Waller $(1950,1952)$ has demonstrated that the draught homogenizes the milk, that it becomes effective earlier in multiparae than in primiparae, and that it appears to pass through three stages. Newton and Newton $(1950,1951)$ have demonstrated that it occurs more frequently in successful lactations and that it is inhibited by fear, pain, anger, embarrassment and by an injection of adrenalin. They have shown also that the reflex can be stimulated by an injection of posterior pituitary hormone (cf. Gunther and Stanier, 1949). Miller (1952) has associated failure of the draught with failure of lactation. However, little of this accumulating knowledge of the draught reflex has yet been applied to the actual problems of lactation.

\section{Method of Investigation}

The draught itself was investigated in four different ways: (a) Subjective sensation of the mother, (b) intermittent leaking or rapid flow observed by the mother, nurse or doctor, $(c)$ by closely observing the sucking movements of the baby while feeding and $(d)$ by the use of the breast pump or hand expression of the breasts.

Observations were recorded on four groups of women.

Group 1. Group 1 were primiparae passing consecutively through the wards of a maternity hospital. They received routine hospital care, were not told about the draught and were sent a written questionnaire after six months' lactation. They had no personal contact with me except by letter to ensure that I personally did not affect their answers.

Group 2. Group 2 were consecutive admissions to a mothercraft home, both multiparae and primiparae; these I watched personally and most were asked to note any sensations, but were not told that they would be followed up.

Groups 1 and 2 were examined in the puerperal period and followed up after six months by a written questionnaire and were requested to write if they felt that they had more information to contribute. One hundred and six did so, 20 in detail. The following information was requested:

MATERNAL. Sore or cracked nipples; overloaded breasts; mastitis or breast abscess; leaking breasts; fall in supply on returning home; too rapid flow; not enough or too much milk; housing and other worries.

BABY. Difficulty in sucking; fighting at the breast; wind; colic; frequent stools; vomiting; general condition and incidents at 3 and 6 months; weight at 3 and 6 months.

FeEDING. Duration; partial or entire at 3 and 6 months; reason for weaning.

DraugHT. (This is described as the tingling or drawing sensation of milk coming into the breast that some mothers feel during or between feeds'.) Occurrence; time in relation to feeds; duration; on one or both sides; when first felt; nature of sensation, e.g. strong, moderate.

Group 3. Group 3 was a small selected group of seven mothers (four primiparae and three multiparae) who were accurate observers and who kept detailed studies during the whole of lactation, observing relation of draught to feeds, timing, duration and factors influencing it. This included my own fourth lactation in 1951.

Group 4. Group 4 consisted of 33 interested mothers who kept records during the establishment of lactation. They were mainly selected from my paediatric clinic or the Carpenter Mothercraft Home and were representative of a wide social and intellectual field.

In addition, over a three-year period I closely observed breast feeding in a 60-bed maternity hospital, a 10-bed mothercraft home and a follow-up clinic where particular note of the draught reflex in normal and troubled lactations was made and observations by mothers were verified.

\section{Observation of Draught}

Subjective Sensation of the Mother. This is a very distinct feeling which she has no difficulty in recognizing once she has felt it, although from my own experience I could appreciate that it could become so much a part of one's everyday life as to be almost subconscious, unless especially observed. It is described in many ways: as 'pins and needles', 'tingling', 'drawing feeling', 'rushing down feeling' or a 'kind of pain' sometimes associated with slight nausea. Most mothers could note the time of onset in relation to feeds fairly accurately, as it starts sharply. Most had difficulty in estimating the duration of a sensation that gradually decreases in intensity. Associated symptoms may occur in the puerperium, e.g. after pains, bleeding per vaginam, and intestinal colic.

Evidence of Intermittent Leaking or Rapid Flow. When the draught occurs between feeds the milk may leak or gush from the nipples. Two patients who were test weighing after every feed made the spon- 
taneous observation that if they had a shower before the baby's feed, milk poured from the breasts and the subsequent feed was $2 \mathrm{oz}$. less than usual. When the baby is put to one breast, milk may be seen flowing from the other but the loss does not seem to be as great as indicated above. This coincides with the subjective sensation of the mother and in some patients will resemble a fountain spurting.

Observation of Sucking Movements of the Baby. In established lactation, three stages of feeding can be seen: (1) The baby sucks or nibbles the nipple with only occasional swallows, often in a restless, hungry fashion for a period lasting a few seconds to a minute. (2) It then becomes quite still, sucking and swallowing in a regular rhythmic fashion with closed eyes and intense concentration for a period of one to three minutes. (3) It begins to move again, sucks in a more leisurely fashion or even stops and goes to sleep, until moved to the other side when it again sucks and swallows in a rhythmical fashion, but without the concentration of the first side. Similar observations have been made in rabbits (Cross and Harris, 1952). Close observation of the baby feeding during the establishment of lactation will often show whether the milk is 'down', whether it is flowing or is coming down intermittently.

Use of Electric Breast Pump or Manual Expression. This sometimes shows when the draught is occurring. Suction may be applied for $\mathbf{3 0}$ seconds or more before the milk flows from the first breast which can then be emptied in a few minutes. The other side can then be emptied without any wait as the milk is 'there'. If the draught has occurred before the feed the milk usually flows easily on suction and the breasts can be emptied in a few minutes.

In some patients one can observe periods when milk comes intermittently with intervals of no milk. It is essential that the patient should be used to the pump or the reflex may be inhibited.

There was no appreciable difference in the observation made on the draught reflex by Groups 1 and 2. Therefore the observations concerning the 241 mothers in Groups 1 and 2 will be analysed together.

\section{Incidence of the Draught Reflex}

Of the 241 patients in Groups 1 and 2 lactation had failed at three months in 38 and was still being carried on at six months by 160 (128 fully feeding). Of the 160,137 stated that they felt the draught either during or before feeds on one or both sides (121 both sides, 12 on opposite breast when baby was sucking, four no record), 11 did not feel it and 12 did not complete this section of the form. Of the 11 (two partially feeding) who did not feel it, seven filled in 'rapid flow' or 'intermittent leaking', so indicating that they had observed it and four said they could 'see it flowing but could feel nothing'. Four of the 11 were from the same health centre and the form was filled in by the Sister. Unfortunately, though I had verbally explained what the draught was to the sisters, I had not given them the routine letter to mothers. The final results showed that most who left the section on draught blank were women followed through health centres where the Sister had not understood or where the patient's form had been filled in from records only. Mothers recognized what I was talking about with alacrity if they were breast feeding. Of the 38 who were artificially feeding at three months, 18 had not felt anything, 10 felt the draught, and 10 left the section blank.

\section{The Physiological Pattern of the Draught Reflex}

This cannot be reported with mathematical accuracy as so many patients from all four groups contributed observations which had not been anticipated in the questionnaire. My own detailed observations gave a clear picture confirmed by other multiparae. Only a composite picture appears of what happens to the primiparae, as variations seem considerable during the 'establishment of lactation', which may be defined as the period between the start of lactation and the maintenance period when a regular feeding pattern and stable daily output have been attained.

Multiparae. My own record during my fourth lactation was as follows. Occasional weak draughts were felt during the last two weeks of pregnancy when emotionally excited, also a few of feeble intensity were felt during labour. Twenty-four hours after delivery a weak draught sensation occurred with suckling and a stronger one 24 hours later. The breasts then filled and from then on draughts occurred with each feed and between feeds; they varied in intensity and were associated with severe after-pains, intestinal colic and bleeding per vaginam. After-pains became less after the fourth day but bleeding per vaginam still coincided with the draught up to the tenth day. For the first month, the draught was not regular; it sometimes came in 10 seconds after putting the baby to the breast, at other times in 30 seconds and sometimes while getting ready for a feed. It was easily elicited by stimulating the nipple, by thinking or talking of the baby and by taking fluids. It varied in intensity and sometimes occurred twice in a feed and between feeds. By the end of one month draughts occurred regularly 10 seconds after putting the baby to the breast and only occasionally twice during a feed or 
between feeds. The baby was fully breast fed and lactation appeared to be established.

The observations of other multiparae confirmed these findings, except that most appeared to be getting the draught as they prepared for the feed and many were still getting the reflex between feeds at the end of one month.

Primiparae. Most primiparae felt no draughts until the third week of the puerperium or later, and in the case of one in Group 3 not until the eighth week when she was fully feeding for the first time. There happened to be a few in the series who had been instructed in Dr. Waller's technique of prenatal breast preparation and some of these felt the draught in the first week, like the multiparae. The primiparae observed that it was eight weeks before most of them were getting regular draughts, at feed time only, on sensory stimulation of the nipple either by the baby or by washing the nipples. Both multiparae and primiparae observed that during the establishment period the draught was easy to elicit in the following ways: (a) stimulation of the nipple, (b) psychological stimulation, e.g. hearing the baby cry, thinking of feed, (c) taking fluids, $(d)$ full breasts, e.g., at night, (e) having shower or swim, i.e., hot, cold or tactile stimulation, $(f)$ undoing brassiere, i.e., relief of pressure, $(g)$ physical exertion, e.g., running, tennis, involving movement of the breasts.

Observations Common to Both Multiparae and Primiparae. Mothers had been asked to attempt to estimate the time between sensory stimulation and feeling the draught. The interval appeared to be regular for each individual at any particular period, from milk coming at once to 30 seconds, the majority being about 10 seconds. In my own record the reflex was quite regular at 10 seconds for two and a half months. This gradually lengthened to 20 seconds in the third month, 30 in the fourth and by seven months it was taking a full minute to elicit. Supply was failing, weaning was started, and the period lengthened to one and a half minutes when the draught gradually disappeared. I also observed that at the $10 \mathrm{p} . \mathrm{m}$. feed the draught was much more difficult to elicit after the fourth month when, in contrast to other feeds, it was always a minute or longer; this was also noted in my previous lactation. In the previous lactation, at seven months the draught was coming in 45 seconds with a better milk supply.

Both multiparae and primiparae observed that it became less easy to elicit by the end of the first three months when it would only be elicited by sensory stimulation of the nipple. The experience of many mothers was that the draught became more difficult to elicit in the latter months and gradually disappeared at weaning. This was also a common observation in those whose lactation failed early. Two in Group 3 stated that the period remained regular from three months to weaning time then became more difficult to elicit; but the figures given are not sufficiently detailed after three months.

Mothers were also asked to note the duration of the draught. This proved very difficult because of the nature of the sensation which is a strong, sharp, at times almost painful, contraction which gradually decreases in intensity so that the time of disappearance cannot be noted. The results varied from 15 seconds to one and a half minutes and even after sensation ceased milk could still be seen flowing. Many patients noted that at times the draught was slower in coming and seemed to last a shorter time. This appeared to be associated with such factors as embarrassment, fatigue and worry, painful nipples and diminishing supply. I confirmed this on several occasions, e.g. anger aroused just before a feed delayed the draught to two minutes, by which time the baby was fighting and screaming. The questionnaire took housing as a possible factor influencing lactation and it was found that of the 137 who felt the draught and were feeding at six months, 35 had a housing problem $(25 \%)$, but of the 28 artificially feeding at three months, 11 had a housing problem $(39 \%)$.

\section{Variations from Average}

Multiple Draughts During a Feed. This occurs in the first two months and two to four draughts may occur during a feed. These were confirmed by watching the baby feed and checking on the pump. All occurred in the group with feeding troubles and were emotional patients helped by a sedative.

Absence of the Draught Sensation. Primiparae do not feel it for about three weeks but observations by other means confirm that it occurs frequently and irregularly. There appeared to be considerable variation in the sensitivity of different patients. Many felt it only on the opposite side to the side at which the baby was feeding, others at some feeds only, usually the early feeds. A small group of those fully feeding did not feel it at all; three of these and other similar patients were closely observed. Draughts occurred, but most of the patients had big breasts with more sub-cutaneous tissue than usual and all had some feeding difficulties though they had an adequate milk yield.

Variations in intensity appear to occur but until a method can be devised for measuring it that does not inhibit it psychologically and that allows for the probable existence of a sphincter round the nipple (Cathcart, Gairns and Garven, 1948), no comment 
can be made except on subjective sensations and observed rapid flow.

\section{Symptoms in the Baby Correlated with the Draught}

Observations were made on my own clinic patients, the mothercraft home patients, and, retrospectively, on Groups 1 and 2 . I also occasionally noted symptoms in my own babies.

When the draught occurs after the baby goes to the breast and milk pours into the child's mouth, it may react in the following ways: (a) Drink as quickly as possible until the initial gush passes off, without developing any symptoms; (b) gulp, choke and withdraw from the breast, going back when the initial gush is over to finish the feed without developing symptoms; (c) fight and push away the breast and often refuse to go back; $(d)$ gulp as fast as possible swallowing air and milk, and be unable to coordinate sucking, swallowing and breathing in the usual rhythmical manner. This may result in the baby getting such a full stomach that it subsequently vomits the feed or suffers from wind, colic and frequent stools. Some babies were observed to develop a gulping habit so that even after feeds were regulated they still tended to gulp and get wind.

Groups $b$ and $c$ were relieved by 'bringing in the milk' before putting the baby to the breast, i.e., evoking the draught by manual stimulation of the nipple and waiting until the subjective sensation of the draught was diminishing. Group $d$ were also helped by 'bringing in the milk' at the beginning of the feed for a few days or weeks and by sedation of mother and baby. 'Posture feeding' (the mother lying on her back with the baby prone across the chest), which does not make the flow any slower but puts the baby in a better position to manage it, also helped. In most cases there was considerable relief of symptoms.

Where the mother felt multiple draughts, or where it could be demonstrated that the milk was coming down intermittently, the baby swallowed air and had colic.

Where the draught was inhibited and late in coming, the baby tended to fight the breast. I observed on many occasions that after one minute of ineffectual sucking my own baby would start to fight. In the retrospective study, five women stated that fighting the breast was the only trouble they had with breast feeding and this occurred at 5 months in four cases. Several mothers observed that the baby started to fight 'when the milk wouldn't come'. In a few cases fighting was observed with other symptoms in the early weeks, and was associated with cracked nipples and pain inhibiting the draught.

It appears to be worth reporting the following figures from the retrospective study. Underfeeding is almost eliminated as a cause of symptoms in the first three months. Of the 159 babies with satisfactory records, still breast fed at 6 months, 131 were first babies. Eighty babies with either gastro-intestinal symptoms or fighting the breast had mothers who felt the draught, and of these 48 mothers described the draught as strong. Of the 64 babies with no symptoms, whose mothers felt the draught, 25 mothers described the draught as strong.

There appears to be a correlation between strength of the subjective sensation of the draught and leaking breasts, rapid flow and a high yield. The babies, with only one exception, had gastro-intestinal symptoms where strong draught was associated with these three observations though the numbers are too small to make firm conclusions. Also the highest incidence of no symptoms occurred in the 'moderate draught' group who were not troubled by leaking breasts, rapid flow or too much milk.

\section{Discussion}

Occurrence of the draught reflex in at least 137 of the 148 patients breast feeding after six months whose records were complete $(97 \%)$ proves that effective reflex expulsion of milk is essential to successful lactation. This is supported by the high percentage who did not feel it and had resorted to artificial feeding by three months.

The Physiological Pattern. It seems fairly clear that the draught reflex occurs as a contraction of myoepithelial cells surrounding the alveoli from the time milk appears in the breast, i.e., about the third day. These contractions can be felt by multiparae in the first week but not usually by primiparae until about three weeks after delivery or later. During the period of establishment of lactation the draughts occur at feed times, either just before or during feeds, and usually once or twice between feeds. They are easily elicited by a number of factors. The period of establishment appears to be one month or less in multiparae and two months or more in primiparae. The reflex then occurs regularly at feeding times, usually only once, and is elicited by sensory stimulation of the nipple. The reflex gradually becomes more difficult to elicit until weaning time (seven to eight months) when it gradually disappears.

Variations in this pattern, particularly in time, occur but the observations and numbers used were not sufficient to give a final picture. The observations on my own lactation were detailed, but they may, however, have been affected by the need of a complementary feed once daily after three months. 
Symptoms in the Baby Related to the Draught. It appears that two main syndromes may be associated with the strength and timing of the draught reflex. (1) Fighting the breast in response to (a) a gush of milk that is difficult for the baby to manage. This occurs in the first two months. (b) A delay of more than one minute in the draught so that there is no milk in response to suckling and the baby becomes impatient. This occurs later, at about 5 months when the draught is less easy to elicit. (2) Gastro-intestinal symptoms, e.g. vomiting, wind, colic, frequent stools which appear to be due to gulping large quantities of milk and swallowing air associated with incoordination of breathing and swallowing.

It is worthy of note that when the latter syndrome is attributed to 'overfeeding' the mother is often advised to curtail feeds instead of to regulate the flow with the result that lactation gradually fails from incomplete emptying of the breasts. This may be the reason that the syndrome is now more oiten attributed to underfeeding (Wickes, 1952). It is also tempting to correlate the 'three months colic' with the period of establishment of lactation and the irregularity of the draught.

However, these conclusions are only tentative and are presented as a preliminary report. It is necessary to plan a study in which multiparae are observed during the establishment of lactation, recording milk production, leaking breasts, milk pressures, particularly ejection pressures and symptoms in the baby. The high incidence of symptoms and the difficulty in assessing the importance of mothers' observations was largely due to the high incidence of primiparae in the series.

Practical Application and Conclusion. Careful observation of the baby at the breast will not only enable the doctor or health centre sister to observe faults in technique, but also to note the flow of milk and when it occurs. It is important for health centre sisters to be familiar with the draught reflex and its variations, especially in primiparae, and particularly with the fact that the unfamiliar surroundings and the anxious circumstances of a single test feed done in a clinic may inhibit the draught giving a false idea of yield. The simple trick of 'bringing in the milk' first when it tended to pour over the baby has helped to relieve colic in many infants. The practice of washing the nipples before feeding often achieves this, and gently rubbing or handling the nipple will bring down the milk. Actual expression is not necessary unless the baby has developed the gulping habit. It also appears that the practice of the mother of taking fluids before feeding her baby assists the 'let down' by conditioning the reflex. It is not suggested in any way that there are not other causes of swallowing wind, colic and fighting the breast, and no comments made here should detract from the importance of correct technique, position and adequate supply. Despite the insufficient numbers and the incomplete nature of this investigation it was felt that the results should be published as a preliminary to attempting a more detailed investigation, with the help of a physicist and a veterinary physiologist if possible.

\section{Summary}

An attempt is made to assess the place of the draught reflex in human lactation.

It is concluded that the presence of the draught reflex is essential to successful lactation and that over $95 \%$ of patients with established lactation are conscious of the subjective sensation of the draught.

An attempt has been made to describe the pattern of the draught reflex during lactation and some variations are described.

A syndrome in the baby is described that appears to be due to a copious flow of milk associated with a strong draught reflex, i.e., ejected at high pressure. The symptoms are wind, colic, vomiting, frequent stools and sometimes fighting at the breast in the first three months. It is noted that these symptoms are often attributed to overfeeding. Fighting at the breast can also occur as a result of delay in ejection of milk.

The practical application is mentioned and the importance of observing the baby during feeding is stressed.

I wish to express my thanks to Dr. Gordon Tait and Dr. Wallace Freeborn for permission to study the patients at the Carpenter Mothercraft Home and the Royal North Shore Hospital respectively; also to Dr. Margaret Harper for her unfailing interest, to Matron Cook of the Carpenter Mothercraft Home for her interest and cooperation, and to Dr. W. W. Ingram and Dr. F. W. Clements for reading and criticizing this paper. I am particularly grateful to Dr. H. K. Waller for his interest and encouragement and for reading this paper and suggesting alterations.

\section{REFERENCES}

Andersson, B. (1951). Acta physiol. scand., 23, 24

Braude, R. and Mitchell, K. G. (1952). J. Endocr., 8, 238.

Cathcart, E. P., Gairns, F. W. and Garven, H. S. D. (1948). Trans. roy. Soc. Edinb., 61, 699.

Cross, B. A. and Harris, G. W. (1952). J. Endocr., 8, 148.

Duncum, B. M. (1947). Brit. Med. Bull., 5, 253.

Ely, F. and Petersen, W. E. (1941). J. Dairy Sc., 24211.

Folley, S. J. (1947). Brit. med. Bull., 5, 135, 142.

Gunther, M. and Stanier, J. E. (1949). Lancet, 2, 235.

Miller, R. A. (1952). Edinb. med. J., 59, 238.

Newton, M. and Newton, N. R. (1948). J. Pediat., 33, 698.

Newton, M. and Newton, N. R. (1948). J. Ped

Newton, N. R. and Newton, M. (1950). Pediatrics, 5, 726. ,(1951). Amer. J. med. Sci., 221, 691. 
Petersen, W. E. and Ludwick, T. M. (1942). Fed. Proc., 1, 66.

Richardson, K. C. (1947). Brit. med. Bull., 5, 123. Selye, H., Collip, J. B. and Thomson, D. L. (1934). Endocrinology, 18, McKeown, T. (1934a). Surg. Gynec. Obstet., 59, 886.

- (1934b). Anat. Rec., 60, 323.

Waller, H. (1938). Clinical Studies in Lactation, 1st ed. London. (1943). Lancet, 1, 69.
Waller, H. (1947a). Brit. med. bull., 5, 181.

(1947b). Archives of Disease in Childhood, 22, 193.

(1950). Lancet, 1, 53.

- (1952). Brit. J. Nutrit., 6, 210.

Wickes, I. G. (1952). Brit. med. J., 2, 1178.

Whittlestone, W. G., Bassett, E. G. and Turner, C. W. (1952). Proc Soc. Exp. Biol. N.Y., 80, 191, 197.

- and Turner, C. W. (1952). Ibid., 80, 194. 